\section{Characterization of soluble antigens of Staphylococcus spp isolated from dairy farms in Venezuela}

\author{
Lilian Spencer, ${ }^{1}$ Valentina Pedrotti, ${ }^{1}$ \\ Deisy Perdomo, ${ }^{1}$ Andreína Gómez, ${ }^{1}$ \\ Armando Díaz, ${ }^{2}$ Cristina Castellii ${ }^{1}$ \\ 1Department of Cell Biology, Simón \\ Bolívar University, Caracas; ${ }^{2}$ Department \\ of Morphological and Basic sciences, \\ Faculty of Veterinary, Experimental \\ University of Romulo Gallegos, Guárico \\ State, Venezuela
}

\section{Abstract}

The genus Staphylococcus contains many pathogenic strains that are difficult to differentiate. Given the absence of a specific immunological test to identify autochthonous species, we have characterized soluble antigens (SAgs) using hyperimmune sera from $\mathrm{BABL} / \mathrm{c}$ mice. Ten samples were taken from the farmers' hands and cattle udders on three different farms. The isolated species were identified using the API kit (Staph) and their ability to form biofilms was determined. The species most commonly found in the isolates (90\%) corresponded to the coagulase-negative bacteria and Staphylococcus sciuri (S. sciuri), which presented the ability of biofilm formation, representing the majority (60\%) in this group. We produced SAgs from those Staphylococcus species present in a higher frequency, such as $S$. sciuri, $S$. aureus, and the reference strain, $S$. aureus ATCC 6835. Polyclonal antibodies (PAb) from mice allowed SAgs characterization by enzyme-linked immunoassay (ELISA) and immunoblotting. The humoral response obtained with the PAb by indirect ELISA tests indicated that our hyperimmune sera have a high recognition for all SAgs produced. We also evaluated the hyperimmune sera cross-reactivity between different SAgs by indirect ELISA and immunoblotting assays. The ELISA experiments showed a significant statistical difference in the recognition of $S$. sciuri when compared to SAgs from $S$. aureus. These results showed a high antigenicity and specificity from $S$. sciuri SAgs in immune tests. We identified a specific immunodominant polypeptide of $\sim 31 \mathrm{kDa}$ (p31) from $S$. sciuri SAg, which do not presented cross-reactivity between different SAgs. We concluded that the p31 polypeptide from $S$. sciuri SAg could be used as antigen in a differential diagnosis test for different staphylococcal species

\section{Introduction}

Staphylococci are widely distributed in nature and can be found in the mucus from different animals, foodstuffs, such as meat, milk and cheese, and in the environment, soil, air and water. Some species of staphylococci may present some risks for humans being responsible for pathologies such as peritonitis, endocarditis and infections of the urinary tract. ${ }^{1-3}$ In addition, pathogenic species belonging to the staphylococci genus can cause clinical and subclinical mastitis in dairy cattle. ${ }^{1}$ Based on their ability to produce the enzyme coagulase, these microorganisms can be classified into coagulase-positive (CPS) and coagulase-negative (CNS) staphylococci. Among the CPS staphylococci, the most pathogenic species is Staphylococcus aureus ( $S$. aureus), which is currently considered an emerging pathogen in cases of subclinical mastitis in dairy cows. ${ }^{2}$ Given the absence of a specific immunological test for autochthonous species from Venezuela, we characterized a $S$. sciuri soluble antigen (SAg) as a potential antigen for staphylococcus differential identification. A total of 10 isolates were taken from farm workers' hands and cattle udders on three different farms in Guárico State. The isolate species were identified using the API kit (Staph). We produced SAgs from Staphylococcus species present in higher frequency, where $S$. sciuri was the most common. In order to characterize these antigens, polyclonal antibodies (PAb) were produced in $\mathrm{BALB} / \mathrm{c}$ mice. SAgs were evaluated by enzyme-linked immunoassay (ELISA) and immunoblotting. Since biofilm formation is a characteristic virulence factor, the ability of $S$. sciuri isolates to form biofilms was also evaluated. ${ }^{3,4}$ Our results showed a high antigenicity and good specificity for $S$. sciuri SAgs in ELISA tests, suggesting the use of this antigen in a differential diagnosis for different CNS species.

\section{Materials and Methods}

\section{Staphylococcus isolates}

The study consisted of 10 staphylococcal isolates from the hands and noses of farm workers and cattle udders on three different farms in the north-central state of Guárico, Venezuela. Samples were collected from the palm of the hands and anterior region of the nose of the operators and from cattle udders using a moist swab (Nitrogen) and transported to the laboratory under sterile conditions. The swabs were planted on mannitol salt agar plates (Difco). Typical colonies of Staphylococcus spp were selected and transferred to the
Correspondence: Lilian Spencer, Universidad Simón Bolívar, AP 89000, Caracas, Venezuela. Tel. +58.212.9064221 - Fax: +58.212.9063061 E-mail: lspencer@usb.ve

Key words: Staphylococcus spp, Venezuelan isolates, soluble antigens, bovine subclinical mastitis, ELISA.

Acknowledgements: we thank Dr. Juan Carlos Martinez and Dr. Anthony Holder for helpful suggestions and critical reading of the manuscript. We would also like to thank Dr. Margarita Rodriguez for the generous gift of the Pseudomonas aeruginosa strain.

Funding: this investigation was financed in part by a grant from DEP-USB (Decanato de Estudios Profesionales de la Universidad Simón Bolívar).

Contributions: LS, design of the study, preparation of antigens, performing immunization experiments and immunological assays, data analysis and manuscript writing; VP, preparation of the soluble antigens, immunization experiments, immunological assays, biofilm assays and data analysis; DP, study design, immunoblotting experiments data analysis and manuscript writing; $\mathrm{AG}$, identification of strains and preparation of antigens; $\mathrm{AD}$, isolation from farms and identification of strains; CC, identification of strains.

Conflict of interests: the authors report no potential conflict of interests.

Received for publication: 30 August 2012.

Revision received: 11 June 2012

Accepted for publication: 15 June 2012.

This work is licensed under a Creative Commons Attribution NonCommercial 3.0 License (CC BYNC 3.0).

(C) Copyright L. Rozenfelde et al., 2012

Licensee PAGEPress, Italy

Microbiology Research 2012; 3:e25

doi:10.4081/mr.2012.e25

Universidad Simón Bolívar using sterile swabs (Nitrogen). The swabs were streaked on Trypticase soy agar plates (Difco) immediately after collection. These plates were incubated at $37^{\circ} \mathrm{C}$ for $48 \mathrm{~h}$ and each isolate was grown to check for purity and identified by a Gram staining and catalase test using 30\% hydrogen peroxide. ${ }^{5}$ Staphylococcus identification to species level was performed by the commercial API Staph ${ }^{\circledR}$ method (BioMérieux, France) according to the manufacturer's instructions, and included the reference strain $S$. aureus ATCC 6538. Also, oxidase activity was determined by a commercial oxidase diagnostic kit (BBL DrySlide) and Staphylocoagulase (free coagulase) activity was determined by using rabbit plasma and the tube method. ${ }^{6}$ 


\section{Soluble antigen preparation}

Each isolate was grown in Luria Bertani broth in sterile tubes. The tubes were incubated at $37^{\circ} \mathrm{C}$ in continuous shaking for $48 \mathrm{~h}$. Bacterial cultures were harvested by centrifugation at $3000 \mathrm{~g}$ for $10 \mathrm{~min}$ at $4^{\circ} \mathrm{C}$ in a centrifuge (Beckmann, model J221M) and then the pellet was washed three times with phosphate buffered saline (PBS) $(8 \% \mathrm{NaCl}, 0.2 \% \mathrm{KCl}$, 0.93\% Na2HP04, 0.2\% KH2P04), pH 7.0.

The supernatant from each isolate was discarded and the pellets were resuspended in $10 \mathrm{~mL}$ of PBS. To each pellet of bacteria previously isolated, we added a cocktail of protease inhibitors (1 mM iodoacetamine, $1 \mathrm{mM}$ phenylmethylsulfonyl fluoride, $5 \mathrm{mM}$ ethylenediaminetetraacetic acid, $1 \mathrm{mM}$ benzamidine) and $3 \mathrm{M}$ urea in $5 \mathrm{~mL}$ of PBS. Bacterial cell suspensions were vigorously pipetted to break up aggregates and samples were placed on ice and subjected to sonication for 3 min using an ultrasonic probe (Ultrasonics Ltd., USA) emitting $20 \mathrm{~W}$. This procedure was performed five times and between each pulse, the samples were subjected to freezing and thawing using liquid nitrogen. Finally, the suspensions were centrifuged at $3000 \mathrm{~g}$ for $30 \mathrm{~min}$ at $4^{\circ} \mathrm{C}$, the supernatants were collected as Sags, and their protein concentrations were determined using the Bradford method. ${ }^{7}$ SAgs were stored at $-20^{\circ} \mathrm{C}$ until use.

\section{Hyperimmune sera and ascites fluid}

Ten week-old female BALB/c mice bred under specific-pathogen-free conditions were used in groups of 6 . The first inoculations of SAgs were at $100 \mu \mathrm{g} / \mu \mathrm{L}$ with $100 \mu \mathrm{L}$ of Freund's Complete Adjuvant (FCA) per mouse; subsequently, four inoculations were prepared in the same way but with Freund's Incomplete Adjuvant (FIA). All these inoculations were administered by intraperitoneal injection. Another group of 10 healthy mice were used as control. Water and food were allowed ad libitum. After the last inoculation, animals were sacrificed under deep anesthesia with ether and exsanguinated by cardiac puncture to collect the serum. In order to obtain antibodies against relevant immunogenic proteins, the most frequently reactive protein, recognized by SAgs serum in immunoblots (see below), was selected to obtain ascitic fluid. This protein was isolated from the nitrocellulose paper, which was pulverized in a mortar and used as antigen after adding 5\% dimethylsulfoxide to the solution. A group of mice were then inoculated intraperitoneally with this antigen in FCA, four times. The ascitic fluid (AF) was collected and polyclonal antibodies (PA) were purified by ammonium sulfate as indicated in the protocol by Harlow and Lane. ${ }^{8}$

\section{Sodium dodecyl sulfate-polyacry- lamide gel electrophoresis}

SAgs were analyzed by sodium dodecyl sulfate-polyacrylamide (SDS-PAGE) on $12.5 \%$ (w/v) polyacrylamide gels. ${ }^{9}$ Protein samples were solubilized in SDS sample buffer (0.15M TrisCl, pH 6.8, 4.6\% SDS, 23\% glycerol, and 0.2 M dithiothreitol (DTT) and $0.1 \% \mathrm{w} / \mathrm{v}$ bromophenol blue) and heated at $100^{\circ} \mathrm{C}$ for $5 \mathrm{~min}$. Protein samples, $10 \mu \mathrm{g}$ per track, were then loaded onto a SDS-PAGE gel; the same concentration of protein was loaded for each isolate. The SDS-PAGE gel consisted of a separating gel $(12.5 \%(\mathrm{w} / \mathrm{v})$ acrylamide/bis-acrylamide, 0.37 M Tris-Cl, pH 8.8, 0.1\% (w/v) SDS, set by the addition of $0.3 \% \mathrm{w} / \mathrm{v}$ TEMED, $0.03 \%(\mathrm{w} / \mathrm{v})$ ammonium persulfate) with a $3 \%$ stacking gel (3\% w/v acrylamide/bis-acrylamide, $0.1 \mathrm{M}$ Tris$\mathrm{Cl} \mathrm{pH} \mathrm{6.8,} \mathrm{0.1 \%} \mathrm{(w/v)} \mathrm{SDS,} \mathrm{plus} \mathrm{TEMED} \mathrm{and}$ $0.05 \% \mathrm{w} / \mathrm{v}$ ammonium persulfate). Electrophoresis was carried out at $120 \mathrm{~V}$ for $1 \mathrm{~h}$ using a Mighty Small II vertical slab gel unit (Bio Rad Instruments). Wide molecular mass markers from Invitrogen (18.3 $\mathrm{kDa}$ to $109.5 \mathrm{kDa}$ ) were used. After electrophoresis, proteins were revealed with silver staining. ${ }^{8}$

\section{Immunoblotting}

After SDS-PAGE, proteins were electrophoretically transferred to nitrocellulose membrane (NCP, Schleicher and Schuell, $0.45 \mu \mathrm{m}$ pore size) to allow immunodetection of the proteins by the antibodies in the sera. The proteins were transferred at $120 \mathrm{~mA}$ in a transblotting chamber (Bio-Rad, Instruments), for $1 \mathrm{~h}$ at $4^{\circ} \mathrm{C}$, using $25 \mathrm{mM}$ Tris- $\mathrm{HCl}, 150 \mathrm{mM}$ glycine, and $20 \%(\mathrm{v} / \mathrm{v})$ methanol. ${ }^{10}$ After transfer, blots were blocked by incubation with a solution of
$3 \%(\mathrm{w} / \mathrm{v})$ non-fat milk in PBS for $30 \mathrm{~min}$ at room temperature, and washed three times (3x) in PBS/T, containing $0.05 \%$ (v/v) Tween20 . Blots were then incubated for $1 \mathrm{~h}$ at room temperature with a solution of primary antibody (hyperimmuneserum) diluted 1:200 in PBS, washed three times and incubated in a solution of affinity purified goat antimouse immunoglobulin conjugated to horseradish peroxidase, at a 1:2000 dilution (Sigma), for 1 $\mathrm{h}$ more. The blots were washed again three times and antibody binding was detected by incubation in a solution of $3 \mathrm{mg} / \mathrm{mL} 4$-chloro-1napthol in methanol, mixed with $50 \mathrm{~mL}$ of 50

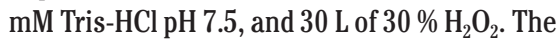
color reaction was stopped by washing with $\mathrm{H}_{2} \mathrm{O}$.

\section{Enzyme-linked immunosorbent assay}

The indirect ELISA test was used to detect specific antibodies present in mouse sera against SAgs. Ninety-six well plates (Immulon 4 from Dynatech) were coated with $100 \mu \mathrm{L}$ per well of SAgs solution, using 1, 5, 10 and 20 $\mu \mathrm{g} / \mathrm{mL}$ of the soluble antigen solution diluted in coating buffer $(0.1 \mathrm{M}$ sodium carbonate/bicarbonate $\mathrm{pH}$ 9.6). Plates were incubated overnight at $4^{\circ} \mathrm{C}$ and washed three times with PBS containing $0.05 \%(\mathrm{v} / \mathrm{v})$ Tween 20 (PBS/T). Plates were then blocked by the addition of PBS containing 1\% (v/v) bovine serum albumin for $30 \mathrm{~min}$ at room temperature, followed by further washing with PBS (3x). One hundred $\mu \mathrm{L}$ of serum diluted 1:200 were added to each well and the plate was incubated at $37^{\circ} \mathrm{C}$ for $1 \mathrm{~h}$. Then, plates were washed three times with PBS and $100 \mu \mathrm{L} /$ well of horseradish
A

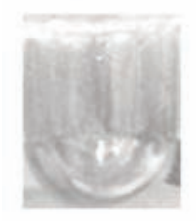

O hrs

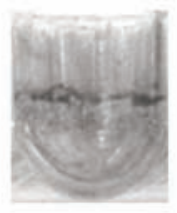

24 hrs
B

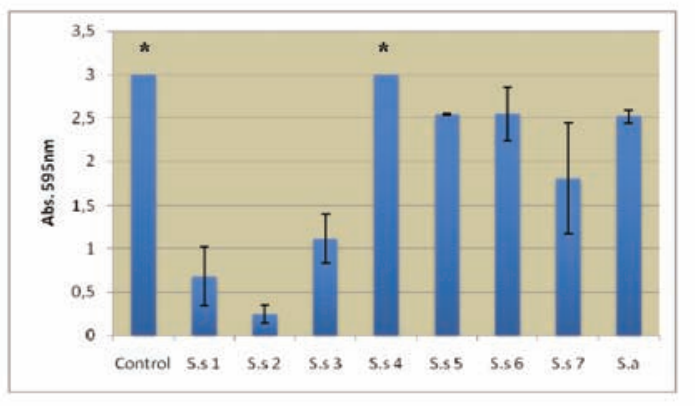

Figure 1. Biofilm formation phenotype. A) This figure shows the formation of biofilm at the air-medium interface, monitored over a $24 \mathrm{~h}$ period for $S$. sciuri. B) Absorbances from crystal violet-stained, surface-attached cells. Dye was solubilized in ethanol and absorbances were read at $595 \mathrm{~nm}$, after $24 \mathrm{~h}$. These values represent the median from six individual experiments. *Absorbance exceeds the threshold limit values. Control used was the Pseudomonas aeruginosa strain, which forms biofilm and the other strains correspond to seven different isolates from S. sciuri (S.s) and Staphylococcus aureus ATCC 6538 (S. a). 
peroxidase-conjugated goat anti-mouse polyvalent immunoglobulin (IgG; H+L) (Sigma) were added at 1:1000 and 1:2000 dilutions. After incubation for $1 \mathrm{~h}$ at $37^{\circ} \mathrm{C}$ the plates were washed again with PBS. The bound conjugated antibody was detected by the addition of $100 \mu \mathrm{L}$ of azino-bis (3-ethylbenz-thiazoline-6-sulfonic acid) (ABTS, Sigma) as substrate, pH 5.0 containing $0.05 \%(\mathrm{w} / \mathrm{v}) \mathrm{H}_{2} \mathrm{O}_{2}$. The reaction was stopped by the addition of $50 \mu \mathrm{L} 2 \mathrm{M} \mathrm{H} 2 \mathrm{SO} 4$ per well. The plates were read in a microplate reader (Bio-RAD i-Mark), using Titer-soft Software (Flow) to measure the absorbance at $405 \mathrm{~nm} .{ }^{8}$ Ten normal mice sera were used as a negative control. The conditions of the indirect ELISA test were determined using different concentrations of antigens and conjugates, and conditions were selected that showed significant differences between NS and hyperimmune sera using different SAgs.

\section{Biofilm formation assay}

Screening for biofilm formation in $S$. sciuri isolates was also evaluated. This assay is based on the ability of the bacteria to form extracellular polysaccharides on polyvinylchloride microplate wells. The biofilm was detected by staining with crystal violet, solubilizing the dye in ethanol and determining the absorbance at 595 nm. ${ }^{11}$ S. sciuri was assessed for biofilm formation as a potential virulence factor and the bacterium Pseudomonas aeruginosa $(P . a)$ was used as positive control. ${ }^{3,12}$ All tests were carried out three times.

\section{Statistical analysis}

Each experimental value is presented as the mean of six replicates \pm standard deviation. Once normality and homogeneity criteria were satisfied, statistical analyses were carried out by one-way analysis of variance; $\alpha=5 \%$ $(\mathrm{P}<0.05)$ was considered significant.

\section{Results}

In this study, 10 isolates from three farms from Zaraza, Guarico State were identified using commercially available API Staph tests and other complementary tests, such as, Gram staining, coagulase, catalase, hemolysis, and oxidase tests (data not shown). These results are summarized in Table 1. The most frequently identified isolate was $S$. sciuri, (6 out of the 10 isolates) and the remaining isolates were: $S$. hominis (2 out of 10 isolates), S. epidermis and $S$. aureus (1 out of 10). Figure 1 shows the biofilm formation of the most frequently isolated species which was $S$. sciuri. Panel A shows the biofilm formation as a potential of this sample monitored over a $24 \mathrm{~h}$ period. Panel B shows the absorbance at $595 \mathrm{~nm}$ from the crystal violetstained isolates and S. aureus ATCC 6538, which was used as a reference. The control test was $P$. aeruginosa, which produced an absorbance over 3 units, similar to S.s 4 isolate. Isolates S.s 5, S.s 6, and S.s. 7, showed absorbances between 1.5 to 2.5, and the isolates S.s 1, S.s. 2 and S.s 3 isolates were under 1 unit of absorbance. These isolates (S.s 1,2 and 3) did not produce a biofilm (data not shown). Considering these results, the isolate S.s. 4 was disrupted by sonication to prepare soluble antigens. The SAgs polypeptide profiles from the $S$. sciuri isolates were analyzed by SDS-PAGE. After silver staining, several polypeptides were observed and the SAg from $S$. sciuri and $S$. aureus species gave characteristic and distinct polypeptide profiles (Figure 2).

The hyperimmune sera from inoculated

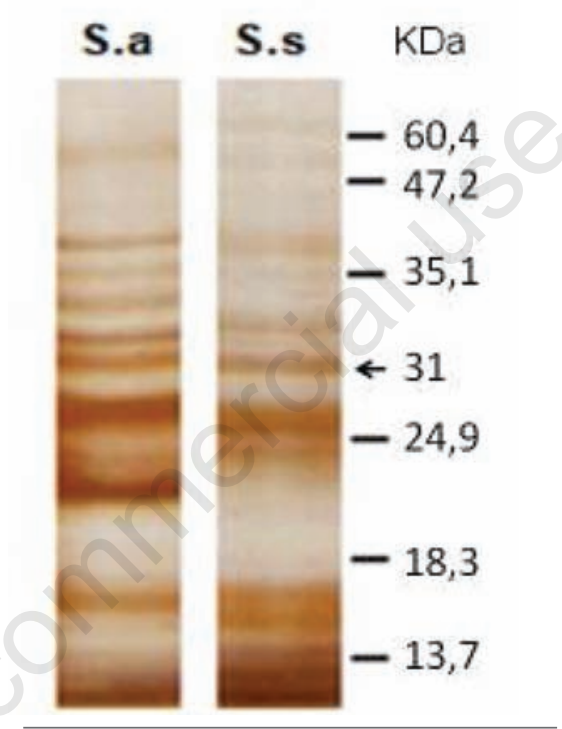

Figure 2. Soluble antigens polypeptides profiles from $S$. sciuri (S.s) and $S$. aureus (S.a) isolates prepared with protease inhibitors after SDS-PAGE (12.5\%) and silver staining. Molecular mass standards $(\mathrm{KDa})$ are indicated at the right. The arrow shows the $\sim 31 \mathrm{KDa}$ polypeptide.

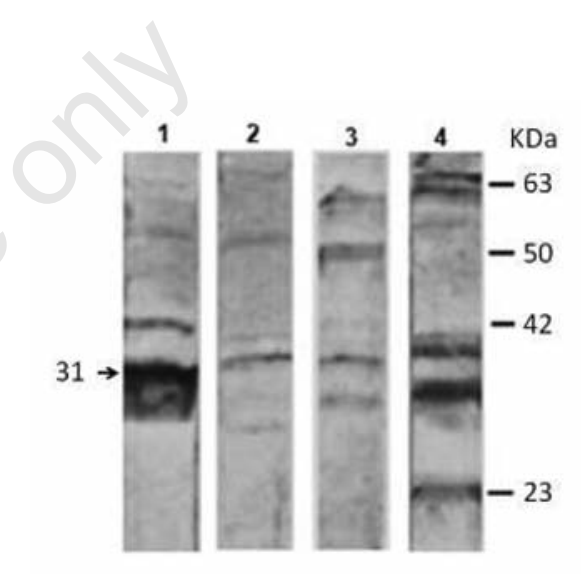

Figure 3. Hyperimmune sera immunoblots showing the IgG responses produced after six weeks of inoculation with soluble antigens isolates. Hyperimmune serum from $S$. sciuri recognizing the $S$. sciuri soluble antigen (Line 1). Hyperimmune serum from $S$. sciuri recognized the soluble antigens $S$. aureus ATCC 6538 (Line 2). Hyperimmune serum from $S$. aureus recognizing the $S$. sciuri soluble antigen (Line 3 ), and hyperimmune serum from $S$. aureus ATCC 6538 recognizing the $S$. aureus ATCC 6538 soluble antigen (Line 4). Molecular mass standards (KDa) are indicated at the right. The $\mathrm{p} 31$ is indicated with an arrow.

Table 1. Biochemical tests applied to Staphylococcus strains isolated from three cattle farms located in Zaraza city, Guarico State, Venezuela.

$\begin{array}{llcccc}\text { Species } & \text { Sample origin } & \text { No. of isolates } & \text { Coagulase test } & \text { Catalase test } & \text { Hemolysis test Oxidase test } \\ \text { S.ciuri } & \begin{array}{l}\text { Udder and tail of cattle } \\ \text { Nose of worker }\end{array} & 6 & - & + & \gamma \text {-hemolysis } \\ & \text { Milk } & & & + \\ \text { S. epidermidis } & \text { Hands of worker } & 1 & - & + & \gamma \text {-hemolysis } \\ \text { S. hominis } & \text { Hands of worker } & 2 & + & + & \beta \text {-hemolysis } \\ \text { S. aureus } & \text { Udder } & 1 & + & + & \beta \text {-hemolysis } \\ \text { Staphylococcus aureus } & \text { Reference } & & + & -\end{array}$

ATCC 6538

Species were identified using the commercial Kit API Staph (BioMerieux, Marcy-l'Etoile, France). In addition, we used other tests such as coagulase, oxidase and catalase to characterize the isolates. The most frequent species isolated in animals and workers was $S$. sciuri. 
mice produced after six weeks of immunization with different SAgs were evaluated by immunoblot to demonstrate the IgG responses. In addition, the cross-reactivity between the different antigens was evaluated by developing the blots with heterologous hyperimmune sera (Figure 3).

Hyperimmune serum from $S$. sciuri recognized three polypeptides of 50,40 and $31 \mathrm{kDa}$ in $S$. sciuri $\mathrm{SAg}$, with the highest recognition for the $31 \mathrm{kDa}$ polypeptide (line 1 ). In the same way, the serum from SAg S.a ATCC 6538 immunized mice recognized five polypeptides in the homologous antigen (line 4). The hyperimmune serum from S.s recognized two bands in S. aureus ATCC $6538 \mathrm{SAg}$ (line 2) and hyperimmune serum from $S$. aureus ATCC 6538 recognized four bands in $S$. sciuri SAg (line 3 ). The intensity of the cross-reaction in immunoblotting was very faint. The most immune dominant polypeptide from $\mathrm{SAg} S$. sciuri detected by immunoblot was p31.

The optimal conditions obtained from ELISA standardization were: $10 \mathrm{~g} / \mathrm{mL}$ for all SAgs and a 1:2000 dilution of conjugated antibodies; these conditions were used in all ELISA tests. Figure 4 shows the ELISA test results from S. sciuri SAgs and antibodies from the different sources. The titers of AF, PA and hyperimmune sera were determined down to a 1:12800 antibody serial dilution to establish the antigenicity. All the IgGs recognized the $S$. sciuri SAg and showed high titers in all cases, especially the IgG from S.s hyperimmune serum with an absorbance approximately 4-6 times higher than that of NS. Indirect ELISA was used to determine the specificity of antibodies from different sources to each SAg and the cross-reaction between the sera (Figure 5). In this experiment, there was a significant recognition of the S.s Sag by the antibody against p31 from AF when compared to antigens from S.a and S.a ATCC 3568. Purified antibodies showed lower absorbance values (Figure 5) that could be due to a low yield from the purification technique. The recognition of S.s SAg by its own antibodies is specific (Figure 5). The results with S.a SAg showed a cross-reaction with all the sera (Figure 5), but recognition was always lower when the hyperimmune sera from S.a were tested against other antigens.

\section{Discussion}

We have isolated 10 Staphylococcus strains from farmers' hands and cattle udders, and identified them by biochemical tests as shown in Table 1. These results showed a high prevalence of CNS bacteria such as $S$. sciuri, followed by $S$. hominis and $S$. aureus. Thorberg and co-workers studied the ability of different
CNS species in dairy herds to induce a persistent infection of subclinical mastitis. ${ }^{13}$ They showed that $S$. epiderminis was mainly found in multiparous cows and $S$. chromogenes in primiparous cows. Also, they reported that $S$. sciuri is one of the most common findings in udder, which agrees with our results. In addition, CNS bacteria have been considered as a group of emerging pathogens that are responsible for subclinical mastitis in some countries. ${ }^{2,13,14}$ Many pathogenic strains have the capacity to form biofilms so this characteristic is considered a potential virulence factor. Despite the fact that $S$. sciuri has never been reported as an etiological infectious agent, our results showed the ability of this species to form biofilm (Figure 1). This property could allow $S$. sciuri to adhere to and colonize the mammary gland. ${ }^{4,15,16} S$. sciuri has been isolated from central venous catheters in humans and this species produced biofilms, suggesting that $S$. sciuri could be involved in human infections. ${ }^{17}$ These results, together with the low milk production of the cattle reported by farmers, could indicate in the present study a correlation with subclinical mastitis. Nevertheless, Oliver and colleagues investigated the invasive potential of biofilm-formation Staphylococci from bovine subclinical mastitis isolates and compared them with primary cell cultures with fluorescent rRNA probes. ${ }^{12}$ They found that biofilm formation does not influence the invasion capacity of $S$. aureus in mastitis. Although biofilm formation is not fully implicated as a

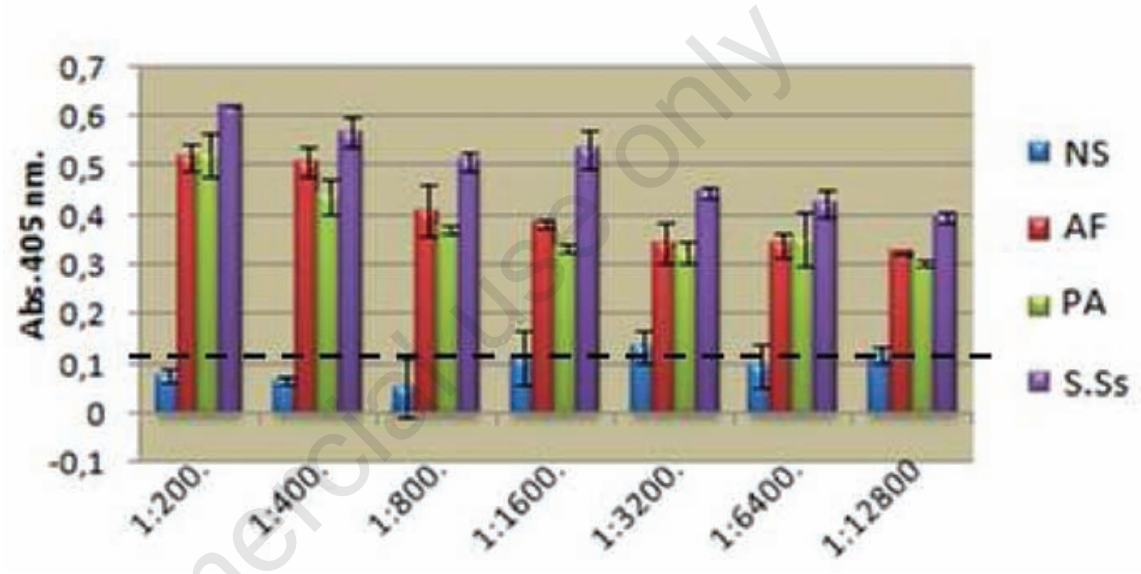

Figure 4. Titers for hyperimmune sera bound to $S$. sciuri soluble antigens $(10 \mathrm{ug} / \mathrm{mL})$ in enzyme-linked immunoassay test. Bars represent the absorbance read at $405 \mathrm{~nm}$ and the discontinuous line the cut off value for negative sera $(0,117$ D.O). NS, negative serum; AF, ascitic fluid; PA, antibody against $\mathrm{p} 31$ purified by ammonium sulfate precipitation; $\mathrm{S}$. Ss, serum from $S$. sciuri soluble antigen.

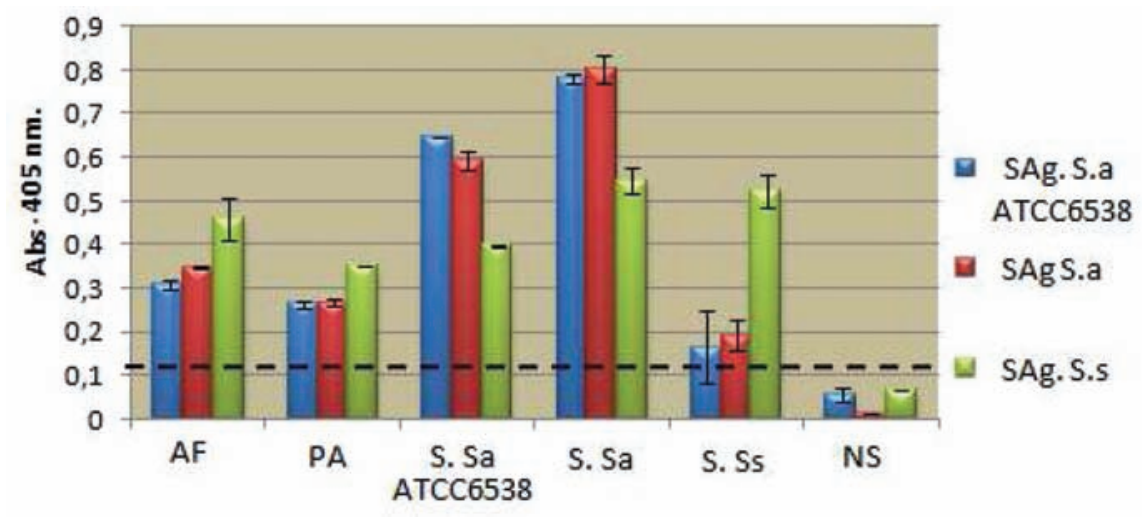

Figure 5. Evaluation of soluble antigens from Staphylococcus strains from isolates and reference strain $S$. aureus ATCC 6538 by indirect enzyme-linked immunoassay using different sources of polyclonal antibodies. Bars represent the absorbance read at $405 \mathrm{~nm}$ and the discontinuous line the cut off value for negative sera. AF, ascitic fluid from p31; PA, purified antibodies by ammonium sulfate precipitation; S. Sa ATCC 6538, serum from S. aureus ATCC 6538; S. Sa, serum from S. aureus; S.Ss, serum from S. sciuri; NS, negative serum; SAg, soluble antigen. 
pathogenic characteristic, it could be an important factor in allowing bacteria to adhere and colonize the mammary gland. This study showed that SAg preparations from different isolates induced high antibody responses in ELISA and immunoblotting tests. We isolated several $S$. sciuri and the S.s 4 isolate was chosen to evaluate the humoral response in experimental $\mathrm{BALB} / \mathrm{c}$ mice. Our results demonstrated that SAgs from isolates were good immunogens because they were able to activate the mices' humoral response and produced hyperimmune sera that could be used to characterize the different isolates. As shown in Figures 2 and 3, the SAg preparations demonstrated different protein patterns for $S$. aureus and $S$. sciuri, a $S$. sciuri polypeptide of about $31 \mathrm{kDa}$ that could be observed with silver staining (Figure 2). Immunoblot analyses using SAg hyperimmune sera against $S$. sciuri Sag strongly recognized a polypeptide of $\sim 31 \mathrm{kDa}$ (p31) which did not show a cross reaction with S. aureus ATCC 6538 SAgs (Figure 3). In the same way, hyperimmune sera from $S$. aureus also recognized a polypeptide of $\sim 28 \mathrm{kDa}$ that was not recognized in $S$. sciuri SAg. This polypeptide could be observed in the silver stained gel (Figure 2). We obtained polyclonal antibodies against p31 and demonstrated that this polypeptide was a good antigen for immunodiagnosis and could be used as a differential diagnostic tool. Previous studies reported the use of whole-cell SDS-PAGE band patterns in the identification of Staphylococcal species. ${ }^{18,19}$ However, Sacilk and colleagues analyzed different CNS species by SDSPAGE and concluded that the polypeptides patterns obtained from whole-cell preparations were difficult to interpret. ${ }^{20}$

\section{Conclusions}

This is the first study to report using soluble antigens to assess their potential in a Staphylococcus differential diagnosis. Our results suggest that, in Venezuela, an ELISA test based on the p31 molecule could be used as a differential diagnostic test between staphylococcal species. Future research should be orientated toward purifying the p31 polypeptide in order to use it as a specific antigen for ELISA tests or to producing a monoclonal antibody for capture ELISA. Each geographical region should study its own isolates of staphylococcal species in order to obtain the best antigen to identify their native species.

\section{References}

1. Pitkälä A, Haveri $M$, Pyörälä $S$, et al. Bovine mastitis in Finland 2001 - prevalence, distribution of bacteria, and antimicrobial resistance. J Dairy Sci 2004;87: 2433-41.

2. Taponen $S$, Pyörälä $S$. Coagulase-negative staphylococci as cause of bovine mastitis. Not so different from Staphylococcus aureus? Vet Microbiol 2009;134:29-36.

3. Hensen SM, Pavicić MJ, Lohuis JA, et al. Location of Staphylococcus aureus within the experimentally infected bovine udder and the expression of capsular polysaccharide type 5 in situ. J Dairy Sci 2000;83: 1966-75.

4. Almeida RA, Oliver SP. Interaction of coagulase-negative Staphylococcus species with bovine mammary epithelial cells. Microb Pathog 2001;31:205-12.

5. Christensen GD, Simpson WA, Younger JJ, et al. Adherence of coagulase-negative staphylococci to plastic tissue culture plates. A quantitative model for the adherence of staphylococci to medical devices. J Clin Microbiol 1985;22:996-1006.

6. Mulder JG, Degener JE. Slime-producing properties of coagulase-negative staphylococci isolated from blood cultures. Clin Microbiol Infect 1988;4:689-94.

7. Bradford MM. A rapid and sensitive method for the quantitation of microgram quantities of protein utilizing the principle of protein dye binding. Anal Biochem 1976;72:248-354.

8. Harlow E, Lane D. Antibodies: a laboratory manual. New York: Cold Spring Harbor Laboratory; 1988.

9. Laemmli UK. Cleavage of structural proteins during the assembly of the head of bacteriophage T4. Nature 1970;227:680-5.

10. Towbin H, Staehelin T, Gordon J. Electrophoretic transfer of proteins from polyacrylamide gels to nitrocellulose sheets: procedure and some applications. Proc Natl Acad Sci USA 1979;76:4350-4.

11. 0`Toole GA, Kolter R. Initiation of biofilm formation in Pseudomonas fluorescens WCS365 proceeds via multiple, convergent signalling pathways: a genetic analysis. Mol Microbiol 1998;23:449-61.

12. Oliveira M, Bexiga R, Nunes SF, et al. Invasive potential of biofilm-forming Staphylococci bovine subclinical mastitis isolates. J Vet Sci 2011;12:95-7.

13. Thoberg BM, Danielsson-Tham ML, Emanuelson U, et al. Bovine subclinical mastitis caused by different types of coagulase-negative staphylococci. J Dairy Sci 2009;92:4962-70.

14. Pyörälä S, Taponen S. Coagulase-negative staphylococci. Emerging mastitis pathogens. Vet Microbiol 2009;134:3-8.

15. Davison TJ, Dohoo IR, Donald AW, et al. A cohort study of coagulase negative staphylococcal mastitis in selected dairy herds in Prince Edward Island. Can J Vet Res 1992; 56:275-80.

16. Hensen SM, Pavičić MJ, Lohuis JA, et al. Use of bovine primary mammary epithelial cells for the comparison of adherence and invasion ability of Staphylococcus aureus strains. J Dairy Sci 2000; 83:418-29.

17. Crump JA, Collignon PJ. Intravascular catheter-associated infections. Eur J Clin Microbiol Infect Dis 2000;19:1-8.

18. Clink J, Pennington TH. Staphylococcal whole-cell polypeptide analysis: evaluation as a taxonomic and typing tool. $\mathrm{J}$ Med Microbiol 1987;23:41-4.

19. Pennington TH, Harker C, ThomsonCarter F. Identification of coagulase-negative staphylococci by using sodium dodecyl sulfate-polyacrylamida gel electrophoresis and rRNA restriction patterns. J Clin Microbiol 1991;29:390-2.

20. Sacilik SC, Osmanağaoğlu Ö, Sayar AH, et al. Availability of use of total extracellular proteins in SDS-PAGE for typing Staphylococcus aureus and coagulase-negative Staphylococci. Turk J Biol 2001;25: 145-51. 